\title{
The program management process with sustainability considerations
}

Gilman Chi Keung Tam

SKEMA Business School, Lille, France

\begin{abstract}
Program management has been widely accepted as an effective tool for making strategic and tactical changes. A brief review of the program management process showed that the ambiguityreduction learning loop together with the uncertainty-reduction performance loop would make program management a feasible sustainability-oriented management tool for addressing the needs of a sustainable society. The requirements and impacts of sustainability are becoming important considerations in formulating a program; however, not much related literature can be found within the project management body of knowledge. This paper aims to facilitate the understanding of "Sustainability in Program Management". Sustainability considerations adopting a three pillars approach is proposed. A "Program Sustainability Assessment Framework" is constructed to help the program manager incorporate sustainability considerations into program management practices. The key factors for aligning program sustainability to corporate sustainability strategy are also discussed.
\end{abstract}

Keywords: Program Management; Project Management; Value Management; Program Manager; Sustainability

\section{Introduction}

The Agenda 21 program, adopted at the 1992 Earth Summit in Rio de Janeiro, Brazil, called for a global partnership of governments, business and industry in ensuring a sustainable development (UNCED, 1992) against an increasingly demanding environment which included: disparities between and within nations; worsening poverty; hunger; ill health and illiteracy; and the continuing deterioration of the ecosystems on which we depend for our wellbeing.

The program management process has been widely used by organizations in the new millennium to deliver strategic changes and optimum benefits. The process uses a program to make beneficial changes in a turbulent environment. It is of particular interest to businesses seeking synergistic matches between capability building (projects) and benefit realization (operations).

Although program managers understand the significance of considering environmental and social factors in addition to economic ones, a lack of literature on this subject within the project management body of knowledge can affect their willingness to support sustainability. To cater for better program performance with sustainability considerations, it is necessary to conduct research on such impacts within program management. 
This paper serves as a catalyst in this respect. First, a definition of "Sustainability in Program Management" is provided. Next, a brief review of program management process is given to help identify the point of interaction with sustainability issues. To help program managers integrate sustainability considerations (economic, environmental and social) into the program routine, an evaluation framework is then presented. Without the support of senior executives or program sponsors, program managers' efforts to promote positive sustainability impacts cannot be realised. Hence, the alignment of program sustainability to corporate sustainability strategy is also discussed.

\section{Definitions}

Brundtland defined sustainable development as "the development that meets the needs of the present without compromising the ability of future generations to meet their own needs" (Brundtland, 1987). Her focus was on intergenerational equity and sustainability. This involves a commitment to: "Economic Sustainability - increasing profitability through efficient use of resources (human, materials, financial), effective design and good management, planning and control; Environmental Sustainability - preventing harmful and irreversible effects on the environment by efficient use of natural resources, encouraging renewable resources, protecting the soil, water, air from contaminations and others; and Social Sustainability - responding to the needs of society including users, neighbours, community, workers and other project stakeholders" (Zainul Abidin \& Pasquire 2007).

Tam (2010) suggested a definition of "Sustainability in Project Management" with reference to the definition of project management under the APM Body of Knowledge (APM BoK, $5^{\text {th }}$ edition). The underlined portion in the quote below is taken from the APM BoK (APM 2006):

"The promoting of positive and minimizing of negative sustainability impacts (economic; environmental; and social) within the process by which projects are defined, planned, monitored, controlled and delivered such that the agreed benefits are realized and contributing to a sustainable society."

Two key components are included in this definition reflecting the attributes of sustainability in project management: a) promoting positive impacts and minimizing negative impacts on economic sustainability; environmental sustainability; and social sustainability within the project development process; and b) the recognition of such project benefits realized is contributing to a sustainable society.

To define "Sustainability in Program Management", reference is again made to the definition of program management under the APM BoK. It suggests that the emphasis on sustainability impacts and contribution to a sustainable society is the same as in the definition of "Sustainability in Project Management". The underlined portion below is taken from the APM BoK:

"The promoting of positive and minimizing of negative sustainability impacts (economic; environmental; and social) within the process of coordinated management of related projects, which may include related business-as-usual activities that together achieve a beneficial change of a strategic nature for an organization and contributing to a sustainable society." 


\section{The program management cycle}

Before the Program Standard (PMI 2006) was first published in 2006, there were a number of pioneers who suggested the scope, definitions, applications and benefits of program and program management for practitioners. A "program" is "a collection of change actions purposefully grouped together (projects and operational activities - e.g. a power utility company has a program to reinforce transmission and distribution network structure in a region while it maintains electricity supply to customers as their normal operation) to realize strategic and/or tactical benefits" (Murray-Webster \& Thiry 2000; Thiry 2004a). A program includes a lifecycle of formulation; organization; deployment; appraisal; and dissolution phases.

The scale of a program can be large or small depending on the situation. Some programs may be of relatively short time frame (e.g. replacement of all $33 \mathrm{kV}$ overhead lines that are more than 20 years old); while others, such as cultural change, may take many years. A program consisting of projects and operations may be independent of, or included in, other projects or programs. Program location within the portfolio setup depends on strategic decisions or operational tactics.

Program management, as described by Thiry, is mainly a purposeful strategic decision management process, grounded in change and aimed at the effectiveness of solutions. It can include projects and non-project actions. It is a management process that addresses both decision making as well as decision implementation (Thiry 2004a). Project management focuses on delivering results and benefits of clear objective(s) within the constraints of scope, time, cost and quality. It is based on a performance paradigm (Thiry 2002) embedded in an "uncertaintyreduction" process (Winch, Usmani \& Edkins 1998). Program management is different from project management in the sense that it focuses on delivering strategic benefits to the organization through the program setup. A program is established with reference to synergistic factors such as strategic benefits, coordinated planning, shared resources, project interdependencies, optimized pacing etc. The goal of a program is to gain benefits that may not be available if projects are carried out individually.

In delivering strategic benefits through strategic decision making and change actions, the management has to deal with internal and external stakeholders with different agendas. This creates ambiguity and requires an "ambiguity-reduction" process such as the "learning loop" to nurture an effective means for strategic decision making. Thiry et al. have advocated Value Management ${ }^{1}$ (VM) based on the learning loop approach to address strategic decision making, and continue to retain the project performance loop approach to implement change actions within the program paradigm (Thiry 2004a). In essence, project management is concerned with efficiency (do the project right) and program management is about effectiveness (do the right project).

\footnotetext{
${ }^{1}$ Value Management (VM) is a management approach for maximizing the overall performance of an organization. It is based on the principles of adding measurable value, focusing on objectives and concentrating on function to enhance innovation. The European Commission recognized the power of VM in delivering competitive advantage to its users, and has developed a European Standard BS-EN 12973:2000 to capture the essence of VM and provide a framework for its applications.
} 
Figure 1 shows that the Program Management process is composed of two elements, namely, Value Management (Learning Loop) and Project Management (Performance Loop). The process of project management has been widely recognized as an effective means to deliver outputs. The program team is responsible for identifying appropriate change actions (projects), which are to be carried out by the project team. The program team may utilize VM as provided in the European Standard BS-EN 12973:2000 to identify beneficial changes.

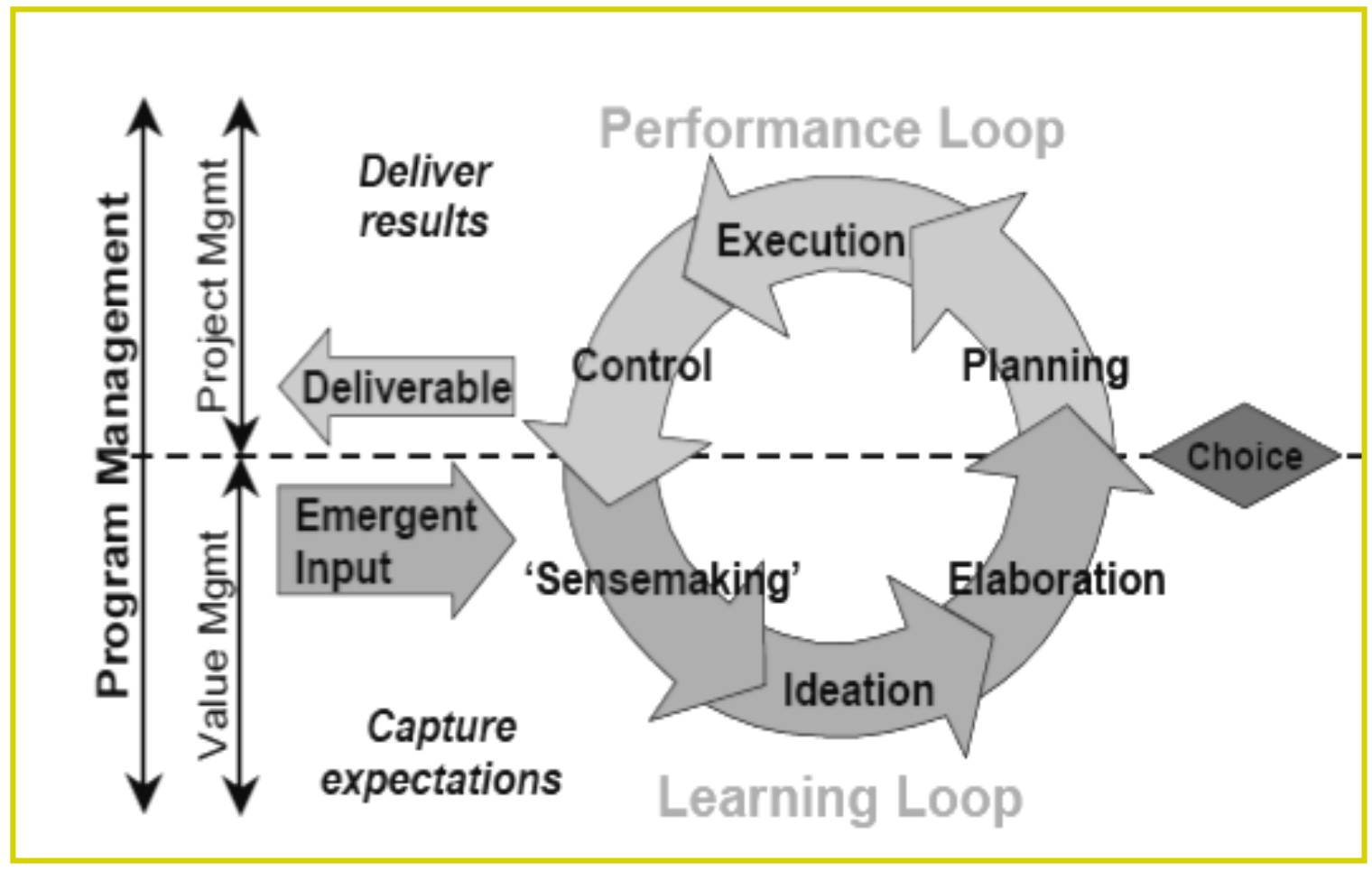

Figure 1. The integrated program management cycle model

Source: Michel Thiry 2002

The Value Management Standard recognizes that VM is distinct from most other management systems and uniquely brings together four key principles: (a) a management style based on value; (b) positive human dynamics; (c) consideration of external and internal environment; and (d) effective use of methods and tools (Technical Committee DS/1 (BSI), 2000). These four key principles set the theme that links the program and/or organizational strategic decisions to change actions.

The VM process emphasizes: (a) sensemaking to understand the situation and come to a shared agreement about the critical success factors and key performance indicators; (b) ideation for generation of innovative alternatives; (c) elaboration for viable option(s) through the evaluation of alternatives on achievability and contribution to the expected benefits; (d) choice of the best option(s) with reference to prioritizing the critical success factors; and (e) mastery of benefits based on a formative evaluation and control process which focuses on the improvement of value 
(Thiry 2004b). The process is iterative in nature and requires adjustment of outcomes and decisions should emergent input to the process occur.

Ambiguity reduction under the learning-based value loop involves considering strategic benefits as a whole, and where sustainability considerations can be part of the process. Although some of the sustainability impacts can only be assessed qualitatively, including such considerations in the formulation of a program will generate a comprehensive overview. Uncertainty reduction under the performance-based project loop requires management to plan and clarify the work to be done in advance, and indicate where sustainability management will be part of the plan. Hence, program management is not only capable of handling strategic perspectives and organizational effectiveness, but its learning approach is also useful in enabling the program team to address community concerns about environmental sustainability on top of economic performance.

\section{Sustainability in program management}

Mohamed Eid (2002), in his paper at the PMI Research Conference 2002, gave the example of the construction industry in the UK, where companies face the challenge of having to integrate vital environmental and social considerations into their day-to-day management. According to Eid (2002: 206), "The goal of sustainability is the process of systematically and effectively integrating vital environmental and social concerns into economic development, financial planning, and project management'. In his opinion, the integration of project management, sustainability and industry competitiveness (for example, quality, markets, equitable market conditions, etc.) would deliver a clearer business case for sustainable construction.

Sustainability is essentially not a methodology but a thinking dimension (Jaafari 2007). It is linked to what people perceive for a change in behavior, attitudes, and consumption patterns, etc. towards sustainability and equity, and how society perceives and values the environment. The context in which Brundtland's definition is embedded indicates that 'needs' include a sound environment, a just society and a healthy economy (Diesendorf 2000).

Program management unlike project management is concerned more with effectiveness than efficiency. With emergent input in a turbulent environment, a program manager makes use of current information (sensemaking) to identify options (ideation) for comparison (elaboration) and decision (choice). Once the decision is made, the project manager will take over the project(s) where sustainability is a consideration. In other words, for sustainability in program management, the program manager emphasises the learning loop leading to a 'Choice'.

To assess sustainability, some authors took a three pillars approach on economic, environmental, and social aspects (Tam 2010; Zainul Abidin 2005). Others use two intersecting pillars (ecological and human) or five pillars (ecological, economic, political, social and cultural). Gibson (2006) took a non-pillar approach to present a set of general sustainability requirements, titled "Core Generic Criteria" (Appendix 1), that sustainability-oriented decision makers need to consider. The three pillars approach is adopted in this paper.

With the three pillars approach, the program manager has to assess the suggested program options in the dimensions of economic sustainability, environmental sustainability, and social sustainability before making a 'Choice'. Depending on the context, the program manager would 
ask a number of questions within each dimension to assess the program sustainability impacts. The following questions serve as examples, but are not exhaustive.

Economic Sustainability: Is it a cost-effective program using whole-life costing? What is its profitability? Does it build up project capability? How is economic risk assessed? Is there any impact (positive or negative) on corporate image? Does it comply with legal requirements?

Environmental Sustainability: Does the program minimize land utilization? Does it have a negative impact on the environment or on bio-diversity or the ecology? Does the program maximize the use of renewable resources (including energy resources) and minimize the use of non-renewable resources?

Social Sustainability: Does it pose any potential health and safety risk for the community? Are community concerns about cultural heritage being addressed? Will community consultation on the program be conducted? Is there any opportunity to hire local underprivileged people? Will the social benefits and costs of the program be equitably distributed?

Chen, Li and Turner (2007: 483) cite the opinion of the US National Academy of Sciences (NAS, 2005) that it is becoming important to adopt quantitative in addition to qualitative environmental management to understand the influences of environmental considerations in business decisions throughout the project lifecycle. It is equally important for the program manager to assess sustainability impacts of various dimensions within the program management cycle using both qualitative and quantitative measures whenever feasible.

\section{Program sustainability assessment framework}

Griffiths (2007) pointed out that a sustainability management framework would ensure that environmentally sustainable practices are included in the design, construction and operational phases of the project, and will take into account the social and economic aspects of project performance. The framework ensures that sustainability considerations in the program's learning loop are taken care of.

Raising awareness of program sustainability impacts and developing mindsets within the program team to establish a culture of care for the environment and people (stakeholders) is important. Program team members and program managers, in particular, need to ensure that the program meets not only the projected economic return but also respects the environment and the needs of the communities involved. Understanding what sustainability means at a big picture level as well as what it means at a tangible day-to-day level is part of the challenge (Griffiths 2007).

The program sustainability assessment framework as shown in Figure $\mathbf{2}$ adopts a three pillars approach of economic sustainability, environmental sustainability, and social sustainability. It builds on the integrated program management cycle model by Michel Thiry (2002). Program sustainability assessment is program context dependable. This means that sustainability considerations for a program on a wind farm development, for instance, are different from the program of waste treatment in a community. 


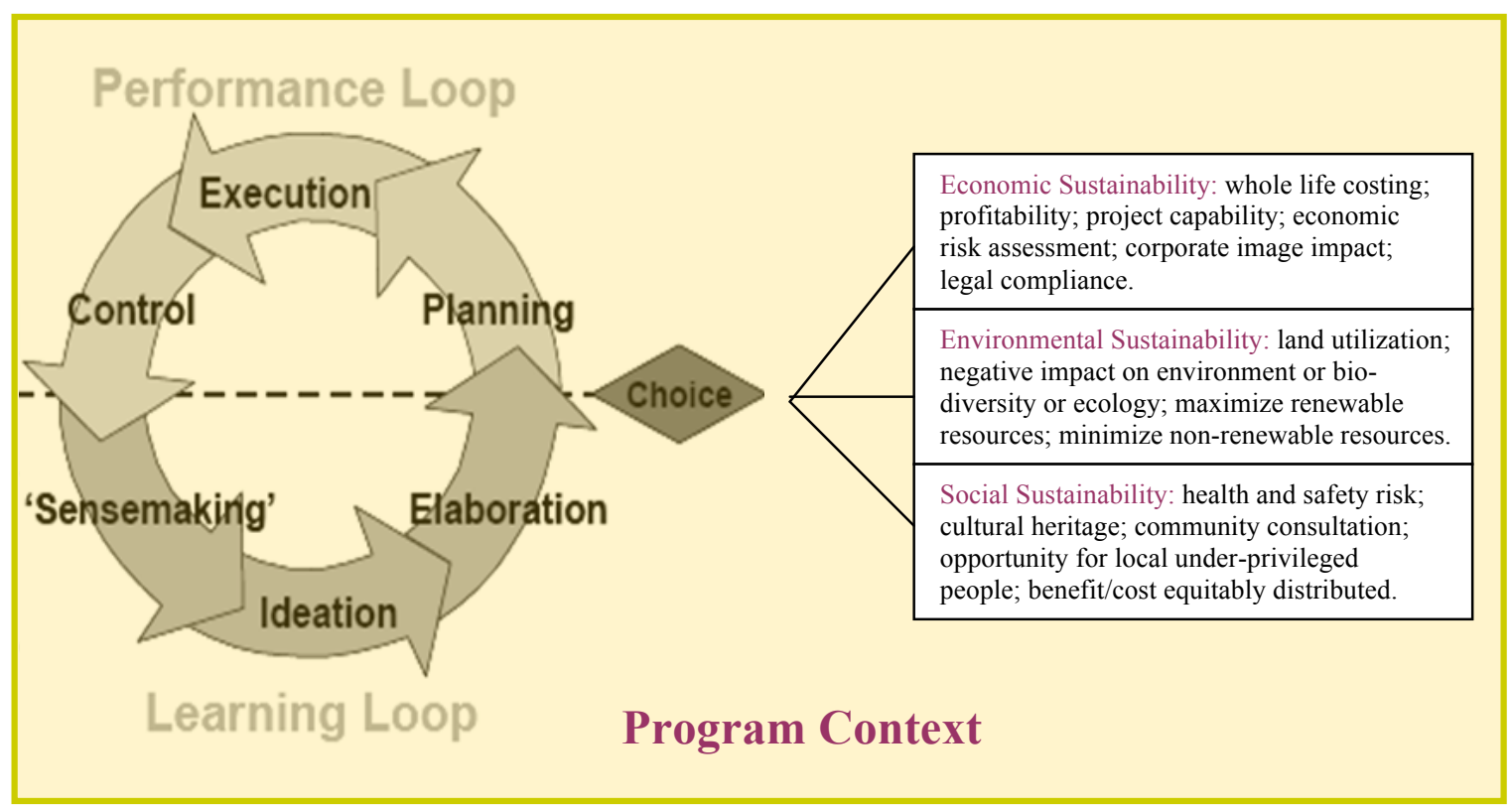

Figure 2. Program sustainability assessment framework

The framework shows that when the program team is developing a program by means of sensemaking, ideation and elaboration in the learning loop, sustainability considerations have to be included in the 'Choice' process. It is necessary to ensure that the various options or related projects of the program chosen will not only bring economic benefits for the survival of the business, but will also consider environmental sustainability and social sustainability to be critical issues for the long-term success of business.

Assessment of the program options in the elaboration process for choice aims to promote positive sustainability impacts and minimize negative impacts in the three dimensions. The program manager together with team members should be able to develop competence in understanding various sustainability issues, and identifying the impacts of the project options. The program manager should be capable of making a balanced decision, or even a trade-off on chosen solutions with a target to maximize overall positive sustainability effects.

The sustainability assessment should be part of the learning loop rather than being conducted after the program is chosen based on purely economic considerations. When the chosen program is being established, the project managers will be responsible for the project sustainability of their respective projects. The program manager like the project manager should refer to their previous program and project experience, including the nature of the program and its context to identify appropriate potential impacts of interest. The list under various sustainability dimensions in the assessment framework above is non exhaustive; nevertheless, it can be taken as a starting point for program managers to identify relevant sustainability requirements for assessment. 


\section{Alignment to corporate and portfolio sustainability objectives}

Although the determination of scope of program sustainability within a program relies on the program manager's experience and knowledge in a similar setting, a number of factors would affect program performance in this respect. To ensure that a sustainability-oriented program manager is appointed, senior executives or the program sponsor must have the knowledge and commitment for putting in place sustainability-related strategies and systems to facilitate program manager's learning loop and performance loop activities.

If senior executives or program sponsors do not have sufficient sustainability knowledge to motivate the program manager, or they do not feel it to be important, then the program manager's efforts alone are unlikely be successful. Hence, the program sponsor or their superiors must have the responsibility to foster an environment (including training and development of the program team) that encourages program sustainability. Furthermore, program stakeholders, whether internal or external, need to be monitored at all times, because they can either help (influence positively) or hinder (influence negatively) those predetermined program outcomes.

The alignment of program sustainability to corporate sustainability strategy is critical to overall sustainability performance. Guidance in the development of a corporate sustainability strategy sometimes comes from governments and industries that have established minimum compliance standards or best practices for corporations (Epstein 2008). The program manager, in formulating program sustainability during the learning process, should align to these corporate guidelines.

To drive program sustainability towards meeting corporate sustainability strategy, various management systems, such as systems for collecting whole-life costing; environmental information; and performance evaluation; etc. are designed and instituted. Epstein (2008) gave the example of Sony - the company uses an intranet-based data system to collect sustainability information from its sites worldwide. Managers at each site input data on energy, water, waste, and other environmental costs, which allows Sony to track its impact on the environment. Without appropriate management systems, it is difficult to reap all the benefits associated with sustainability performance. The program manager should organize an effective program sustainability performance evaluation system to integrate economic, environmental, and social objectives and reward the contributions of team members on their individual as well as group achievements.

The major challenge to successful implementation and alignment of program sustainability to corporate sustainability strategy is not building the hardware system, but the development of sustainability-oriented people system. Mui and Sankaran (2004) pointed out that the project management body of knowledge does not cover sustainability as a knowledge area. They suggested that such an essential knowledge area should be included in the project management body of knowledge and emphasis should be placed on a multidisciplinary and integrated approach (Mui \& Sankaran 2004).

Mui and Sankaran (2004) suggested that sustainability development (e.g. urban renewal project) requires project managers acting as generalizing specialists to adopting a holistic perspective and cradle-to-grave approach in managing projects. These suggestions apply equally to program 
managers. Even though program management is in a form of cyclic process, program managers need a holistic perspective and cradle-to-grave approach.

Appropriate training and development of program and project managers on sustainability competence is important in transforming them into generalizing specialists (project management specialist with general sustainability knowledge). Jaafari (2007) recommended teaching sustainability through project-based learning to professionals, rather than discipline-based learning, as the former provides a paradigm for creativity and achievement of balanced solutions through engagement in realistic assignments under mentoring with special focus on the sustainability dimension.

\section{Conclusions}

The Agenda 21 from the 1992 Earth Summit calls for a global partnership of governments, business and industry for sustainable development. The increasingly demanding challenges in sustainability (economic, environmental, and social) have necessitated governments, business and industry to seek appropriate tools for better performance. The program management process equipped with a framework for sustainability considerations is capable of meeting the strategic and tactical challenges in today's turbulent environment.

At the heart of program management is value management in the learning loop, and the project management in the performance loop. The embedded ambiguity-reduction learning loop in the program management process helps to understand program context by 'Sensemaking', develop various options by 'Ideation', and compare the options through 'Elaboration'. Sustainability considerations sit in the 'Choice' process to ensure that the chosen program is contributing to a sound environment, a just society and a healthy economy.

The definition of "Sustainability in Program Management" is used to delineate the boundaries of sustainability considerations within the realm of program management. Two key components are included in this definition, reflecting the attributes of sustainability in program management: a) promoting positive impacts and minimizing negative impacts on economic sustainability, environmental sustainability, and social sustainability within the program development process; and $b$ ) the recognition that the realization of such program benefits contributes to a sustainable society.

The program manager like the project manager should refer to their previous program and project experience, including the nature of the program and its context, to identify appropriate potential impacts of interest. For sustainability in program management, the program manager should put more emphasis on the learning loop leading to a 'Choice'.

The three pillars approach in assessing economic sustainability, environmental sustainability, and social sustainability is adopted in constructing an assessment framework. Sustainability is essentially not a methodology but a thinking dimension. However, it is recommended that sustainability impacts be assessed using both qualitative and quantitative measures wherever feasible. Sample questions in each dimension are provided as a reference.

Raising the awareness of program sustainability impacts and developing mindsets within the program team to establish a culture of care of the environment and people (stakeholders) is 
important. Nevertheless, there is no published guideline from major project management associations available to help project professionals in this regard. Hence, senior executives or the program sponsor should put in place the relevant strategy or system for fostering program sustainability; otherwise, the efforts devoted by the program manager alone are unlikely to be successful.

Program sustainability should be aligned to the corporate sustainability strategy. To drive program sustainability towards corporate objectives, appropriate management systems to gauge program performance are required. The development of sustainability-oriented people systems to enhance sustainability competence is critical not only for delivering program sustainability, but also for achieving corporate sustainability. Further research to gain better understanding of sustainability in program management is recommended.

\section{References}

APM (Association for Project Management) 2006, The APM Body of Knowledge, 5th ed., Association for Project Management.

Brundtland, G.H. 1987, Our Common Future, Oxford University Press.

Chen, Z., Li, H. \& Turner, R. 2007, Managing the environment, in J.R. Turner (ed.), Gower Handbook of Project Management 4th ed., Gower Publishing, Aldershot, UK.

Diesendorf, M. 2000, Sustainability and sustainable development, in D. Dunphy, J. Benveniste, A. Griffiths \& P. Sutton (eds), Sustainability: The Corporate Challenge of the 21st Century, Allen \& Unwin, Sydney, 19-37.

Eid, M. 2002, A sustainable approach to the project management odyssey, paper presented at the PMI Research Conference 2002: Frontiers of Project Management Research and Application, Seattle, WA.

Epstein, M.J. 2008, Making Sustainability Work: Best Practices in Managing and Measuring Corporate Social, Environmental, and Economic Impacts, Berrett-Koehler Publishers, San Francisco, CA.

Gibson, R.B. 2006, Sustainability assessment: basic components of a practical approach, Impact Assessment and Project Appraisal, vol. 24, no. 3, 170-182.

Griffiths, K. 2007, Project sustainability management in infrastructure projects, paper presented at the 2nd International Conference on Sustainability Engineering and Science, 20-23 February 2007, Auckland, New Zealand.

Jaafari, A. 2007, Thinking of sustainability as a dimension of managerial competency, PM World Today, vol. ix, no. ix.

Mui, D.H.F. \& Sankaran, S. 2004, An effective project management-based application model for sustainable urban renewal in Hong Kong, Project Management Journal, vol. 35, no. 4, 15-34.

Murray-Webster, R. \& Thiry, M. 2000, Managing programmes of projects, in R. Turner \& S. Simister (eds), Gower Handbook of Project Management, 3 ed., Gower, Aldershot, UK, 47-64.

NAS 2005, Decision making for the environment: social and behavioral science research priorities, National Academy of Sciences, Washington, DC.

PMI (Project Management Institute) 2006, The Standard for Program Management, Project Management Institute, Newtown Square, PA.

Tam, G.C.K. 2010, Sustainability competence requirements for project manager, paper presented at the IPMA International Expert Seminar 2010 - Survival and Sustainability as Challenges for Projects, 18-19 February 2010, Zurich, Switzerland.

Technical Committee DS/1 (BSI) 2000, PD 6663: Guidelines to BS EN 12973: Value Management - Practical Guidance to its Use and Intent, British Standards Institution, Chiswick, UK.

Thiry, M. 2002, Combining value and project management into an effective programme management model, International Journal of Project Management, vol. 20, no. 3, 221-227.

Thiry, M. 2004a, Program management, ch. 12, in P.W. Morris \& J.A. Pinto (eds), The Wiley Guide for Managing Projects, John Wiley \& Sons, New York.

Thiry, M. 2004b, Value management, ch. 36, in P.W. Morris \& J.A. Pinto (eds), The Wiley Guide for Managing Projects, John Wiley \& Sons, New York.

UNCED 1992, Agenda 21, Chapter 1: Preamble, United Nations Conference on Environment \& Development. 
Winch, G., Usmani, A. \& Edkins, A. 1998, Towards total project quality: a gap analysis approach, Construction Management and Economics, vol. 16 no. 2, 193-207.

Zainul Abidin, N. 2005, Using value management to improve the consideration of sustainability within construction, unpublished $\mathrm{PhD}$ thesis, Loughborough University, UK.

Zainul Abidin, N. \& Pasquire, C.L. 2007, Revolutionize value management: a mode towards sustainability, International Journal of Project Management, vol. 25, no. 275-282.

\section{Appendix 1. Core generic criteria for sustainability assessment (Gibson, 2006)}

\begin{tabular}{|l|l|}
\hline & \multicolumn{1}{|c|}{ Core Generic Criteria } \\
\hline 1 & Socio-ecological system integrity \\
\hline 2 & Livelihood sufficiency and opportunity \\
\hline 3 & Intra-generational equity \\
\hline 4 & Inter-generational equity \\
\hline 5 & Resource maintenance and efficiency \\
\hline 6 & Socio-ecological civility and democratic governance \\
\hline 7 & Precaution and adaptation \\
\hline 8 & Immediate and long term integration \\
\hline
\end{tabular}

About the author:

Gilman C. K. Tam has a MSc degree with distinction in Energy from the Heriot-Watt University in the U.K. and MBA degree from the Newport University in the U.S. He is a PhD candidate at SKEMA Business School (Lille, France). He has gained extensive practical experience in electrical plant construction, commissioning, and maintenance within power station environment both in Hong Kong and China. He has also built a good track record in the development of coal-fired power plant and other energy saving projects in China. Gilman is a member of The Institution of Engineering and Technology (IET) in the U.K.; member of The American Society of Heating, Refrigerating and Air-Conditioning Engineers (ASHRAE); and member of Project Management Institute (PMI) in the United States. He is a PMP (Project Management Professional from PMI) and PRINCE2 Practitioner (from APM Group, U.K.). His major research interests include sustainability in project management and related competence.

Email: gilman.tam@gmail.com 